\title{
Efficacy of Gender and Age on Spirituality and Psychological
}

\section{Well-Being of Adults}

\author{
Aditi Desai ${ }^{1 *}$
}

\section{ABSTRACT}

Adults have to deal with a range of responsibilities, duties and various situational tasks. In order to achieve their individual, social and organizational aims and objectives successfully, adults required to possess a set of skills, competencies and a required level of intelligence. With the evolution of the concept of intelligence, spiritual intelligence has become one of the more influential phenomenons. The objective of present study was to investigate the impact of gender and age on spiritual intelligence and psychological well-being of adults. A sample consisting of 600 adults has taken into consideration from Ahmedabad city. Structured and standardize questionnaires have used to collect primary data for the study. The major finding of the study was that there is a positive relationship between spiritual intelligence and psychological wellbeing of adults. Further results also indicated that both gender and age have significant impact on spirituality and psychological well-being of adults.

\section{Keywords: Spiritual Intelligence, Psychological Well- being}

Over the last few decades, theories of multiple- intelligence have extended our perception of intelligence beyond traditional, creative, practical social, existential and spirituality. Spiritual intelligence is term used to indicate a spiritual correlate to IQ (Intelligence Quotient) and EQ (Emotional Quotient). Like emotional quotient, spiritual quotient is becoming more main-stream in scientific inquiry and psychological discussion. Spiritual intelligence refers to the skills, abilities and behavior requisite to find moral and ethical path to help us through life, which make sure commitment, connectedness and harmony with our inner-self, inter-personal relationships and with the cosmos.

According to Amram (2009), "spiritual intelligence is a kind of ability that causes selfconsciousness, self-control, profound understanding of meaning of life, purposefulness, increase in peace, the ability to communicate effectively with others and mental health. Spiritual

\footnotetext{
${ }^{1}$ Ph.D. Research Scholar, Gujarat University, Ahmedabad

*Responding Author

(c) 2016 I A Desai; licensee IJIP. This is an Open Access Research distributed under the terms of the Creative Commons Attribution License (http://creativecommons.org/licenses/by/2.0), which permits unrestricted use, distribution, and reproduction in any Medium, provided the original work is properly cited.
} 
intelligence is the consequence of the 36 highest level of individual growth in the fields of cognition, meaning attainment, transcendental and moral communication.”

Five components of spiritual intelligence are as follows:

- The capacity to transcend the physical and material.

- The ability to experience heightened states of consciousness.

- The ability to sanctify everyday experience.

- The ability to utilize spiritual resources to solve problems.

- The capacity to be virtuous.

Psychological well-being is perhaps the most widely used construct among mental health professionals and psychologists. However, there is still no consensus regarding the operational definition of this construct .Yet, many theories of well-being have been proposed and an extensive body of empirical research using different indices of this construct has been conducted. However, theorists have found that the concept of psychological wellbeing (PWB) is much more complex and controversial. Practically speaking, psychological wellbeing serves as an umbrella term for many constructs that assess psychological functioning (Girum, 2012). Associations were independent of age, gender, demographic factors, and baseline mental and physical health. We conclude that the wellbeing of the elderly is an important objective for both economic and health policy. Current psychological and economic theories do not adequately account for the variations in pattern of wellbeing with age across different parts of the world. The apparent association between wellbeing and survival is consistent with a protective role of high wellbeing, but alternative explanations cannot be ruled out at this stage (Andrew Steptoe at el., 2014).

\section{Statement of problem:}

The present investigation attempts to "Efficacy of Gender and Age on Spirituality and Psychological Well-being of Adults”.

\section{OBJECTIVES:}

Following objectives were clarified with reference to the nature of problem.

- To study Spiritual Quotient and Psychological well being among adults in relation to gender.

- To study Spiritual Quotient and Psychological well being among adults in relation to age groups.

\section{Significance of the study:}

The present study assesses the status and compares the Spiritual intelligence and Psychological Wellbeing among male and female adults of different age groups. As a result, the concerned bodies of mental health, policy makers, educational institutes, families and governmental and non-governmental organization should work together on adults or strengthen the existing programs in order to increase the Spiritual Quotient psychological well-being. Present research is important for those involved in therapy and counselling to identify adults who are at low level of Spiritual Quotient psychological wellbeing and to develop and improve prevention and 
intervention methods for adults. The finding of present study will also provide important direction to conduct further research in the areas of psychological wellbeing and mental health of adults.

\section{Operational Definitions:}

Spiritual Quotient: Spiritual Quotient (SQ) is described as a measure that looks at a person's spiritual intelligence in the same way as intelligence quotient (IQ) looks at cognitive intelligence. In other words it is the ability to be creative and insightful.

Psychological Wellbeing: Psychological wellbeing is the subjective feeling of contentment, happiness, satisfaction with life's experience and of one's role in the word of work, sense of achievement, utility belongingness, and no distress, dissatisfaction or worry etc. These things are difficult to evaluate objectively, hence the emphasis is on the term "subjective” wellbeing. It may well be maintained in adverse circumstances and conversely, may be lost in favorable situation. It is related to but not dependent upon the physical/psychological conditions.

\section{Hypothesis:}

For the present research process, the following null hypothesizes are formulated:

- (Ho1) There will be no significant difference between the score of Spiritual Quotient among adults in relation to gender.

- (Ho2)There will be no significant difference between the score of Spiritual Quotient among adults in relation to age-groups.

- (Ho3) There will be no significant difference between the score of Psychological Wellbeing among adults in relation to gender.

- (Ho4) There will be no significant difference between the score of Psychological Wellbeing among adults in relation to age-groups.

\section{Research Design:}

The present study was not possible experimentally because of nature of investigation. The researcher has adopted the quantitative descriptive research to gain the objectives of the study. Quantitative Descriptive research includes data collection through questionnaire quantification of the responses of the respondents and fact findings of different kinds. Quantitative Descriptive research involves collecting data in order to test hypothesis or to answer questions concerning the current status of the subjects of the study.

All most all research designs are complex. When, the researcher wants to study simultaneously two or more independent variables, the investigator selects factorial design. A factorial design is the most common way to study the effect of two or more independent variables. In a factorial design, all levels of each independent variable are combined with all levels of the other independent variables to produce all possible conditions.

The 2 X 3 factorial design of the present study is as under. There are 6 cells in the following table each cell contains 100 subjects. 
Table:- 1.1 Showing $2 X 3$ factorial design of the present study

\begin{tabular}{|l|l|l|l|}
\hline \multirow{2}{*}{ Age- Group (B) } & \multicolumn{2}{l|}{ Gender (A) } & Total \\
\cline { 2 - 4 } & Male (A1) & Female (A2) & 200 \\
\hline 20-35 yrs (B1) & 100 & 100 & 200 \\
\hline 40-55 yrs (B2) & 100 & 100 & 200 \\
\hline 60 and above (B3) & 100 & 100 & N=600 \\
\hline Total & 300 & 300 & \\
\hline
\end{tabular}

\section{Variables:}

In the present research, gender and age were taken as Independent Variables. Spiritual quotient and psychological wellbeing of adults were taken as Dependent Variables.

\section{Population:}

The population of the present study consisted adults of various age group in Ahmedabad district (Gujarat State).

\section{Sample:}

For the present research work researcher has selected 600 adults with the help of random sampling technique. Further they were classified in to 2 groups i.e. Male (300) and Female (300). The categorization and details of sample selection were given in following table.

Table:-1.3 Showing categorization and details of sample

\begin{tabular}{|c|c|c|c|}
\hline \multirow{2}{*}{ Age- Group } & \multicolumn{3}{|c|}{ Gender } \\
\hline & Male & Female & Total \\
\hline 20-35 yrs & 100 & 100 & 200 \\
\hline 40-55 yrs & 100 & 100 & 200 \\
\hline 60 and above & 100 & 100 & 200 \\
\hline Total & 300 & 300 & $\mathrm{~N}=600$ \\
\hline
\end{tabular}

\section{Tools:}

The tools for the present study were selected in a manner to achieve an optimum level of confidence by the investigator for the objectives of the study. Since the study principally contained three variables namely values, personality dimension, mental health, therefore such tools were decided to be choosing as could validity and reliably measure these variables. The 
investigator after screening a number of available tests finally selected the following tools to collect the data:

\section{Roqan Spiritual Intelligence Test - by Zainuddin R. and Ahmed, A. (2010):}

To measure the Spiritual Intelligence of respondents, Spiritual Intelligence Test prepared by Prof. RoquiyaZainuddin and Ms. Anjum Ahmed was selected. Test was in English language, this test consisted of seventy eight items. The scale is rated as LikertRatin and judged on five point scale. The points strongly agree, agree, undecided, disagree and strongly disagree are rated as 5, 4, 3, 2, 1, respectively. Zohar and Marshall have classified Spiritual Intelligence in six dimensions. These seventy eight items were based on these six dimensions, which are as under:
a) The inner self
b) The inter self
c) Biostoria
d) Life perspective
e) Spiritual actualization
f) Value orientation

\section{Psychological well being Scale - by Sisodia, D.S. and Choudhary, P. :}

This scale was developed using Likert Technique. The scale comprises of 50 statements with a view to measure several aspects of well being like Satisfaction, Efficiency, Sociability, Mental Health and Interpersonal Relations. This scale is considered to be useful in a variety of research and applied settings such as a quality of index, a mental health status appraisal, and a measure of psychotherapy outcome evaluation and a social indicator of measuring population changes in sense of well-being overtime.

The scale consists of fifty statements. All statements are of positive manner. 5 marks to strongly agree, 4 marks to agree, 3 marks to undecided, 2 marks to disagree and 1 mark to strongly disagree responses are assigned. The sum of marks is obtained for the entire scale. No time limit should be given for completing the scale; however most of the respondents should finish it in 15-20 minutes. Sub scales of test are as follows:
a) Satisfaction
b) Efficiency
c) Sociability
d) Mental health
e) Interpersonal Relation

\section{Procedure of Data Collection:}

The investigator with great interest planned the data gathering soon after selecting sample and finalizing for the research. The investigator with prior permission of the adults of various age groups personally established a good rapport with subjects. Then researcher had explained the 
importance of research work and collected the data after ensuring the confidentiality of them. Each subject was given a questionnaire one after another in the same sequence. All were requested to read all statements one after the other and give their responses in the responses column by choosing appropriate responses for each statement, which they felt correct and appropriate. All the subjects were explained the purpose of the study and what is expected in the questionnaire given to them. They were requested to avoid mutual consultations. Whatever they had doubts, the investigator clarified and explained to them clearly. Time was not limited. The respondents were requested not to leave any item unanswered and incomplete.

\section{Scoring:}

Scoring of the obtained data was done with help of respective manuals available for the test in the present study. The data have been arranged in the respective tables according to the statistical test applied.

\section{Statistical Analysis:}

Descriptive statistical measures mean and standard deviation were used to see general pattern of Spiritual Quotient, Mood States and psychological wellbeing of the respondents according to Gender and age groups. ANOVA (Analysis of variance) factorial design $2 \times 3$, LSD (Least Significance Difference) tests were computed to determine whether there is a significant mean difference between various pairs of adults.

\section{RESULTS \& DISCUSSION:}

Table 1:- Showing Mean, SD \& F value between Male and Female adults for dependent variable Overall $S Q$.

\begin{tabular}{|l|l|l|l|l|l|}
\hline Gender & N & Mean & SD & F & Sig. \\
\hline Male & 300 & 296.61 & 41.40 & \multirow{2}{*}{10.58} & \multirow{2}{*}{$p<.01$} \\
\cline { 1 - 3 } Female & 300 & 304.89 & 36.72 & & \\
\cline { 1 - 4 }
\end{tabular}

As observed in the Table 1 main effect of the first independent variable i.e. Gender is reported significant. The $\mathrm{F}(1,300)=10.58(p<.01)$. The Mean scores of Male and Female adults are 296.61 ( $S D=41.40)$ and 304.89 ( $\mathrm{SD}=36.72$ ) respectively. It means Female adults have greater spiritual intelligence than the male adults. The findings might be interpreted in terms of sensitivity and heart centeredness towards life and a continuous process of ethical check in dealing with day to day life situations.

Table 2:- Showing Mean, SD \&F value of adults of different age groups for dependent variable Overall SQ.

\begin{tabular}{|l|l|l|l|l|l|}
\hline Age-Group & N & Mean & SD & F & Sig. \\
\hline Age Group-I & 200 & 270.81 & 48.46 & \multirow{3}{*}{164.47} & \multirow{2}{*}{$p<.01$} \\
\cline { 1 - 4 } Age Group-II & 200 & 304.41 & 15.27 & & \\
\hline Age Group-III & 200 & 327.03 & 21.54 & & \\
\hline
\end{tabular}


Table 3:- Showing Least Significant Difference (LSD) among various groups

\begin{tabular}{|l|l|l|l|}
\hline S.N. & Pairs & $\begin{array}{l}\text { Mean } \\
\text { difference }\end{array}$ & $\begin{array}{l}\text { Level of } \\
\text { Sig. }\end{array}$ \\
\hline 1 & $\begin{array}{l}\text { Age Group - I v/s Age Group - II } \\
\text { (B1 v/s B2) }\end{array}$ & 33.60 & $p<.01$ \\
\hline 2 & $\begin{array}{l}\text { Age Group - I v/s Age Group - III } \\
\text { (B1 v/s B3) }\end{array}$ & 56.51 & $p<.01$ \\
\hline 3 & $\begin{array}{l}\text { Age Group - II v/s Age Group - III } \\
\text { (B2 v/s B3) }\end{array}$ & 22.61 & $p<.01$ \\
\hline
\end{tabular}

An overview of Table 2 \& 3 highlighted that the obtained Mean values of Age Group - I, Age Group - II and Age Group - III for Overall Spiritual Intelligence are 270.81 (SD=48.46) 304.41 $(\mathrm{SD}=15.27)$ and $327.03(\mathrm{SD}=21.54)$ respectively. Significant F value is to be reported $\mathrm{F}(2,200)$ $=164.47$. $(p<.01)$ Further post hoc comparison LSD test revealed all the three groups i.e. Age Group - I and Age Group - II have significant mean difference 33.60 which is significant at $(p<.01)$. Similarly, Age Group - I and Age Group - III also have significant mean difference $56.51(p<.01)$. As observed in Table that Age Group - II and Age Group - III have significant mean difference 22.61 significant at $(p<.01)$. This wide range of significant mean difference suggested that Age Group - III have higher traits of Spirituality than Age Group - II. On the other hand Age Group - I has less Spiritual Intelligence than Age Group - III and Age Group II.

Table 4:- Showing Mean, SD \& F value between Male and Female adults for dependent variable Overall Wellbeing.

\begin{tabular}{|l|l|l|l|l|l|}
\hline Gender & N & Mean & SD & F & Sig. \\
\hline Male & 300 & 153.69 & 56.66 & \multirow{2}{*}{62.98} & $p<.01$ \\
\hline Female & 300 & 177.89 & 44.36 & & \\
\hline
\end{tabular}

A two way between groups analysis of variance was applied to explore the influence of independent variable gender as observed in table no. 4. The F value is to be reported significant $\mathrm{F}(1,300)=62.98(p<.01)$. Female adults scored higher mean $(\mathrm{M}=177.89, \mathrm{SD}=44.36)$ in comparison of Male adults $(M=153.69, S D=56.66)$. This implies that Female adults have better Psychological Wellbeing than Male adults. Findings might be interpreted as social acceptance for females to vent out pent up emotions in a free way as well as a social comfort to remain a home maker throughout life.

Table 5:- Showing Mean, SD \&F value of adults of different Age Groups for dependent variable Overall Wellbeing.

\begin{tabular}{|l|l|l|l|l|l|}
\hline Age-Group & N & Mean & SD & F & Sig. \\
\hline Age Group-I & 200 & 132.98 & 49.49 & \multirow{3}{*}{182.09} & \\
\cline { 1 - 4 } Age Group-II & 200 & 160.71 & 32.45 & & \\
\cline { 1 - 4 } Age Group-III & 200 & 203.69 & 46.55 & & \\
\hline
\end{tabular}


Table 6:- Showing Least Significant Difference (LSD) among various groups

\begin{tabular}{|l|l|l|l|}
\hline S.N. & Pairs & $\begin{array}{l}\text { Mean } \\
\text { difference }\end{array}$ & $\begin{array}{l}\text { Level of } \\
\text { Sig. }\end{array}$ \\
\hline 1 & $\begin{array}{l}\text { Age Group - I v/s Age Group - II } \\
\text { (B1 v/s B2) }\end{array}$ & 27.73 & $p<.01$ \\
\hline 2 & $\begin{array}{l}\text { Age Group - I v/s Age Group - III } \\
\text { (B1 v/s B3) }\end{array}$ & 70.71 & $p<.01$ \\
\hline 3 & $\begin{array}{l}\text { Age Group - II v/s Age Group - III } \\
\text { (B2 v/s B3) }\end{array}$ & 42.98 & $p<.01$ \\
\hline
\end{tabular}

A perusal of Table 5 \& 6 indicated that Mean values high, medium and low for Age group - III, Age group - II and Age group - I for Overall Wellbeing are 203.69 (SD=46.55), 160.71 $(\mathrm{SD}=32.45)$ and 132.98 ( $\mathrm{SD}=49.49)$ respectively. For second main effect i.e. Age Groups, $\mathrm{F}$ value is to be reported significant $\mathrm{F}(2,200)=182.09(p<.01)$. Further, post hoc comparison(Table-) revealed all the three groups i.e. Age Group - I and Age Group - II, Age Group - I and Age Group - III and Age Group II and Age Group - III have significant mean difference i.e. $27.73(p<.01), 70.71(p<.01)$ and $42.98(p<.01)$ respectively. This level of confidence revealed the fact that age has significant impact on Overall Wellbeing of adults.

\section{DISCUSSION:}

The obtained findings have been interpreted and discussed in the light of available evidences and observations. Discussion has been taken up hypothesis wise. The results of ANOVA on spirituality with reference to gender for present study clearly indicated that gender had significant impact on spirituality. It was hypothesized as mentioned in the first hypothesis that (Ho1) There will be no significant difference between the score of Spiritual Quotient among adults in relation to gender. Thus it is rejected spirituality factors like life perspective, spiritual actualization and over all spiritual quotients. It may be concluded that female respondents are more spiritual than male respondents on life perspective, spiritual actualization and over all spiritual quotients. It means female adults have grater spiritual characteristics such as awareness about the origin and purpose of their life, they are more able to answer questions like what is the meaning of life, why I am here, why are we here etc. Similarly female adults are more creative and have capacity to identify their relationship with others.

However, there are some studies which found that there is significant difference between male and female on spiritual intelligence, a study done by Dwivedi \& Ameta (2015) revealed that females tend to be spiritually more sensitive than males. Most favorable responses were observed for value sensing and community sensing dimensions of spiritual intelligence for both male and female respondents which represents that they usually think about meaning of their life deeply and they are also concerned about the community from which they belong and people surrounding them. Least scores were recorded for the dimension awareness sensing, so individuals need to work on this to improve overall sensitivity. They need to be spare time for themselves and think and understand a deeper level of consciousness. Nazam (2014) also found 
that there was a significant difference between male and female students on composite score of spiritual intelligence.

Further ANOVA results also highlighted that age groups interact significantly with each other on spiritual quotient. Therefore, (Ho2)there will be no significant difference between the score of Spiritual Quotient among adults in relation to age-groupsis rejected. This level of confidence implies that spirituality varies according to age of respondents. So, it can be said that adults of different age respond differently to spiritual phenomenon. Spirituality increases with age, as people become spiritual as they grow older.

Efficacy of gender was reported on psychological well-being of adults. Therefore, (Ho3) there will be no significant difference between the score of Psychological Wellbeing among adults in relation to gender is rejected. This implies that gender have significant impact on psychological well-being of adults. Female adults have greater psychological well-being. As findings show that significant difference were observed among Age groups of adults with reference to psychological well-being among adults. Hence, (Ho4)there will be no significant difference between the score of Psychological Wellbeing among adults in relation to age-groups is strongly discarded for psychological well-being.

\section{CONCLUSION}

The era of stiff competition has resulted into declining human values and increasing pressure among adults. Therefore, adults need strong inner self and willpower to face the challenges of present life situation. The intelligence that a person uses to inculcate strong inner self is called Spiritual Intelligence. Spiritual Intelligence and psychological wellbeing helps adults to manage their day to day life effectively because now they are clear about the real purpose of their deeds and they knows what to do and what not to do. Also, spirituality and psychological wellbeing gives them inner satisfaction which reduces the level of stress in facing in their daily life.

As far as role of gender and age are concerned with the spirituality and Psychological wellbeing of adults, Gender and Age groups have positive impact on the dimensions of Spiritual intelligence and psychological wellbeing among adults.

\section{REFERENCES}

Amram, Y. (2009). The contribution of emotional and spiritual intelligence to effective business leadership. Doctoral Dissertation, Institute of Transpersonal Psychology, California, Palo Alto.

Dwivedi, C, \& Ameta, K.(2015). Does Spirituality helps in managing stress?: A Case Study of Engineering Colleges of Southern Rajasthan. International Journal of Scientific Research. Volume : 4 | Issue : 8 - ISSN No 2277 - 8179.

Garrett, Henry, E. (2005). Statistics in psychology and education. New Delhi: Paragon International Publishers. 
Girum, T. (2012). Psychological wellbeing as a function of religious involvement, spirituality and personal meaning in life among community - residing elders in Dessie Town. M. A. thesis.

Kotnala, S. (2014) A Study of Spiritual Intelligence among Graduate Students. The International Journal of Indian Psychology ISSN 2348-5396 (e)| ISSN: 2349-3429 (p) Volume 3, Issue 1, No.5

Nazam, F. (2014). Gender difference on spiritual intelligence among adolescents. Indian Journal of Applied Research.Vol.4 (11).

Sisodia, D.S. \& Choudhary, P. (2012). Psychological Well Being Scale. National Psychological Corporation, Agra.

Steptoe, A., Deaton, A., \& Stone, A. A. (2015). Psychological wellbeing, health and ageing. Lancet, 385(9968), 640-648.

Zainuddin R. \& Ahmed, A. (2010).Roqan Spiritual Intelligence Test, National Psychological Corporation, Agra.

Zohar, D., \& Marshall, I. (2000). Connecting with our spiritual intelligence. New York: Bloomsbury Publishing House. 